\title{
RADICLE MOMS STUDY: MINORITY STRESS AND IMPLICATIONS FOR LESBIAN MOTHERS
}

\author{
by
}

\section{Sherri Mosovsky}

B.S. in Psychology, University of Pittsburgh, 2003

\author{
Submitted to the Graduate Faculty of \\ the Department of Behavioral and Community Health Sciences \\ Graduate School of Public Health in partial fulfillment \\ of the requirements for the degree of \\ Master of Public Health
}

University of Pittsburgh 


\section{UNIVERSITY OF PITTSBURGH}

\section{GRADUATE SCHOOL OF PUBLIC HEALTH}

This thesis was presented

by

\section{Sherri Mosovsky}

It was defended on

March 29, 2013

and approved by

\section{Thesis Advisor:}

Beth A. D. Nolan, PhD

Senior Associate Director, Assistant Professor

Behavioral and Community Health Sciences, Institute for Evaluation Science in Community Health

Graduate School of Public Health

University of Pittsburgh

\section{Committee Member:}

Nina Markovic, PhD

Associate Professor, Assistant Professor

Department of Dental Public Health, Department of Epidemiology

School of Dental Medicine, Graduate School of Public Health

University of Pittsburgh

\section{Committee Member:}

Ronald Stall, PhD, MPH

Director, Associate Chair for Science, Professor

Center of Lesbian, Gay, Bisexual and Transgender Health Research; Behavioral and

Community Health Sciences

Graduate School of Public Health

University of Pittsburgh 
Copyright (c) by Sherri Mosovsky

2013 
Beth A. D. Nolan, PhD

\title{
RADICLE MOMS STUDY: MINORITY STRESS AND IMPLICATIONS FOR LESBIAN MOTHERS
}

\author{
Sherri Mosovsky, MPH \\ University of Pittsburgh, 2013
}

\begin{abstract}
Millions of Americans are diagnosed with depression each year, costing billions of dollars. Consequences of depression are detrimental to the sufferer and can affect children and significant others, exemplifying the public health significance of this illness. Little is known about depression among mothers who identify as lesbian, even though they may be at an increased risk. The first aim of the Relationships And Depression In Childbearing LEsbian (RADICLE) Moms study was to determine the prevalence rate of depression in a sample of selfidentified lesbian women with at least one child under 18 years of age. The second aim was to investigate minority stress to determine if higher levels of social support reduce the effects of gay stress on depression symptoms. Recruitment efforts targeted counties in two states that had marriage equality and two that did not. A comprehensive survey including standardized depression and stress scales were utilized for assessments. One-hundred-thirty-one self-identified lesbian mothers responded via an anonymous Internet survey. Results indicate that $8.4 \%$ of the sample reported clinically significant levels of depressive symptoms; however, limitations of the sample such as privileged demographics suggest that women in the lesbian mother population at large may experience significantly higher rates of symptoms. After controlling for demographic factors, separate multiple regression analyses were conducted to examine the relationship between depression and social support, gay stress, and general stress. Results show that each
\end{abstract}


significantly predicted depressive symptoms, which implies that increasing social support or reducing general stress or gay stress may alleviate depressive symptoms in this minority population. Recommendations for future research will be proposed. 


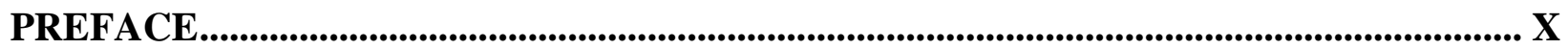

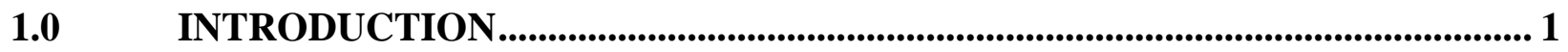

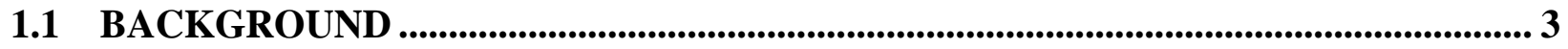

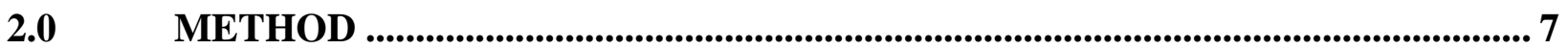

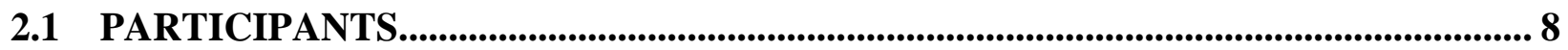

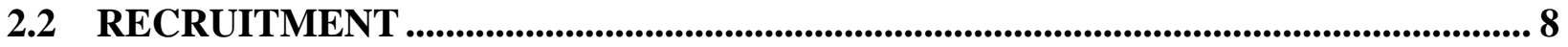

2.2.1 Mailed Recruitment........................................................................................ 8

2.2.2 Emailed and Online Recruitment............................................................... 10

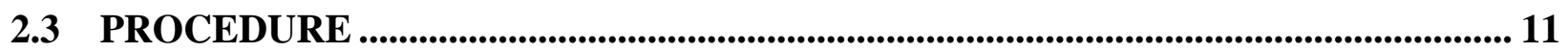

2.4 MEASURES ……................................................................................................................. 12

2.4.1 Demographic Information.................................................................................. 12

2.4.2 Social Support ....................................................................................................... 12

2.4.3 Depression................................................................................................................ 13

2.4.4 Gay Stress ........................................................................................................... 14

2.4.5 General Stress.................................................................................................... 14

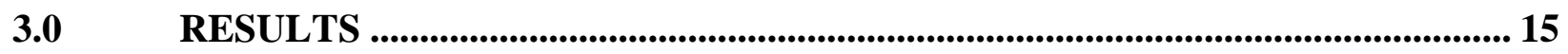

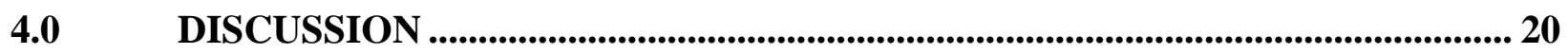

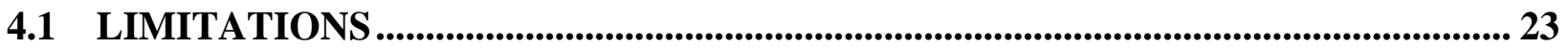

5.0 FUTURE RESEARCH DIRECTION ....................................................................... 27

5.1 BARRIERS TO IDENTIFYING AND TREATING DEPRESSION ........................... 27 
APPENDIX A: FLOW CHART OF SAMPLE REDUCTION TO IDENTIFY LESBIAN

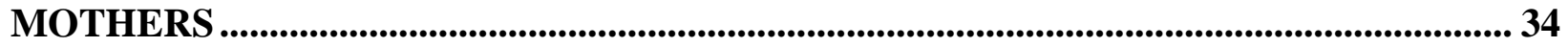

APPENDIX B: BODY OF RECRUITMENT FLYER ................................................ 35

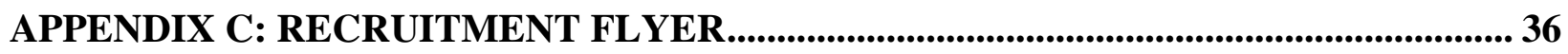

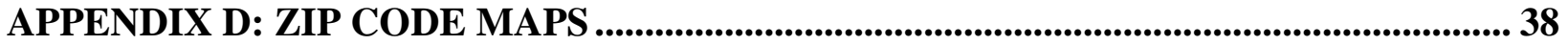

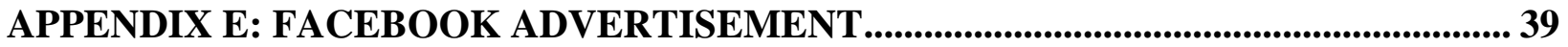

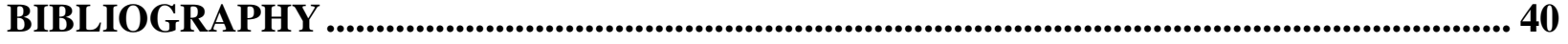




\section{LIST OF TABLES}

Table 1: Participants' Demographic Characteristics as a Percentage of Sample ........................ 15

Table 2: Measures of Stress among Lesbian Mothers (Means, SD, Range).............................. 17

Table 3: Correlations for Measures of Stress among Lesbian Mothers..................................... 18 


\section{LIST OF FIGURES}

Figure 1: Flow Chart of Sample Reduction to Identify Lesbian Mothers ................................ 34

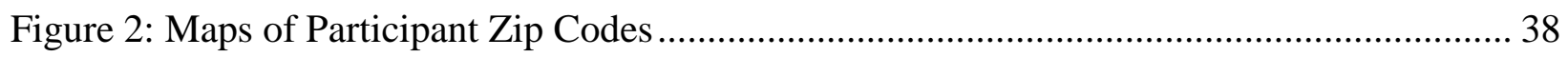

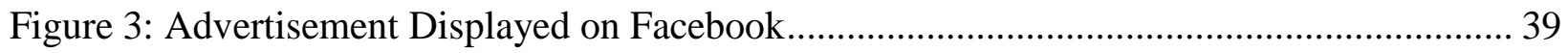




\section{PREFACE}

I would like to thank the members of my thesis committee, Drs. Nina Markovic, Beth Nolan, and Ron Stall for their time and support throughout this project. I am extremely grateful for their mentorship in and outside of the classroom and for the opportunity to learn from their knowledge and experience. Their suggestions and guidance helped steer this study down the path of success.

I would like to thank Drs. Nina Markovic, Beth Nolan, and Martha Terry for their generous funding for the project, without which, the study could not have been to this scale.

I would also like to thank the mothers of the study who selflessly took the time to complete an uncompensated survey to help an unknown student, while most likely juggling work and children.

Hundreds of business, organizations and individuals posted flyers, sent emails, and shared the study link, to which, I am incredibly grateful. Without their help, the study would not have succeeded. I would like to extend a special thanks to the editor of the New England newspaper Bay Windows for donating advertisement space, which recruited a large portion of the participants.

I would also like to thank Tanya Disney, Pallavi Jonnalagadda, Jason Chiu and the students and faculty of the University of Pittsburgh Statistics Consulting Lab for their time and 
help with the data analysis, as well as for their patience with my endless questions and short deadlines. Furthermore, I'd like to thank Catherine Boothby for her help designing the study logo.

Lastly, but most importantly, I would like to thank my family and friends for their unconditional support, love and encouragement. I am especially thankful for my wonderful partner, L. Fusco, who stood by me through setbacks, aggravation, and countless hours of missed activities due to my dedication to this project. I love you all! 


\subsection{INTRODUCTION}

Over 17 million Americans suffer from depression each year (Agency for Healthcare Research and Quality, 2000). Depression, however, does not affect all Americans equally; women experience higher rates than men do (Centers for Disease Control and Prevention [CDC], 2011) and research indicates that lesbian women may suffer more than heterosexual women do (Bradford \& Ryan, 1988; Gilman et al., 2001; Harrison, 1996; Sorensen \& Roberts, 1997; White \& Levinson, 1995). Nevertheless, depression can be variable over the life course so it is important to determine when individuals are most at risk and which factors are most influential. If specific time points or risk factors can be determined, prevention efforts can be directed upon those and depression levels may be reduced or eliminated.

The postpartum period, defined as the 12 months proceeding childbirth, has been extensively studied for incidence of minor and major depressive episodes (Gavin et al., 2005). Postpartum depression (PPD) is common and affects nearly 20\% of mothers to some degree (Gavin et al., 2005). Lesbian mothers appear to be especially susceptible to PPD (Ross, 2005).

There are numerous reasons why lesbian women likely experience higher rates of PPD than heterosexual women. First, a personal history of depression is the most significant risk factor for PPD, which disproportionately affects lesbian women (Cochran, 2001; Frayne, Nguyen, \& Allen, 2009; O’Hara \& Swain, 1996; Robertson, Grace, Wallington, \& Stewart, 2004; Ross, 2005; Trettin, Moses-Kolko, \& Wisner, 2006; van Bussel, Spitz, \& Demyttenaere, 
2006). Second, low social support is a risk factor of PPD (Frayne et al., 2009; O’Hara \& Swain, 1996; Robertson et al., 2004; Ross, 2005; Trettin et al., 2006); studies have found that lesbian women report weaker family ties, whether it be the result of geography or discrimination (Gartrell et al., 1996; Gartrell et al., 2000; Kurdek, 2001; Ross, 2005; Rothblum \& Factor, 2001). Furthermore, lesbian women report less support for childbirth from gay and lesbian friends (DeMino, Appleby, \& Fisk, 2007; Gartrell et al., 1999; Ross, 2005). These are important because support from family and friends can protect against depression (Khatib, Bhui, \& Stansfeld, 2013; Leahy-Warren, McCarthy, \& Corcoran, 2012). Third, high amounts of stress and low social status are risk factors for PPD (McFarlane et al, 2005; Meyer \& Paul, 2011; Ross, 2005; Trettin et al., 2006). Research indicates that lesbian women experience institutional and medical discrimination (Burgess, Tran, Lee, \& van Ryn, 2007; Hatzenbuehler, McLaughlin, Keyes, \& Hasin, 2010). This discrimination may reduce the social status of lesbian women, create high levels of stress, and discourage victims from seeking treatment (Cochran, 2001; Crawford, McLeod, Zamboni, \& Jordan, 1999; Friedman, 1999; Gartrell et al., 1999; O’Hanlan, Dibble, Hagan, \& Davids, 2004; Ross, 2005; Stacey \& Biblarz, 2001; Trettin et al., 2006). The evidence suggesting that lesbian women experience higher rates of PPD than heterosexual women is especially salient since one-third of lesbian women give birth (Gates, Badgett, Macomber, \& Chambers, 2007).

Maternal depression can adversely affect the health of children and significant others (Ahlström, Skärsäter, \& Danielson, 2009; Bulloch, Williams, Lavorato, \& Patten, 2009; Campbell, Morgan-Lopez, Cox, \& McLoyd, 2009; Fanti \& Henrich, 2010; Ishaque, 2009; Santos, Matijasevich, Barros, \& Barros, 2010). Children and significant others demonstrate more internalizing behaviors such as depression and anxiety (Ahlström et al., 2009; Bulloch et al., 
2009; Fanti \& Henrich). Children also experience more externalizing behaviors such as conduct problems and hyperactivity than do children of non-depressed mothers (Fanti \& Henrich, 2010). Research has found that almost one-half of lesbian women want children; nearly 80,000 foster and adopted children live with lesbian, gay, and bisexual (LGB) parents; and two million LGB individuals would like to adopt (Gates et al., 2007). Despite these findings, researchers have not determined the risk or prevalence of PPD in lesbian women (Ross, 2005) or have identified theories or treatment for maternal depression in lesbian women.

The first aim of this project is to determine the prevalence rate of depression in a sample of self-identified lesbian women with at least one child less than 18 years of age. The second aim is to investigate minority stress and determine if higher levels of social support reduce the effects

of gay stress on depression symptoms. Finally, recommendations for future research will be proposed.

\subsection{BACKGROUND}

Several studies have evaluated maternal mental health in lesbian women (Fulcher, Sutfin, Chan, Scheib, Patterson, 2002; Gartrell et al., 2000; Golombok et al, 2003; Patterson, 2001; Ross, Shapiro, Peterson, \& Stewart, 2009; Steele, Goldfinger, \& Strike, 2007). Some studies indicate that lesbian mothers are not at a higher risk for depression compared with heterosexual women (Fulcher et al, 2002; Gartrell et al., 2000; Golombok et al, 2003; Patterson, 2001). Caution must be taken, however, when interpreting these results. First, lesbian women experience unique risk and protective factors that may influence depression expression differently than for heterosexual 
women. Second, although these studies were groundbreaking and extremely important, they contain numerous limitations making a definitive judgment about depression impossible.

The Contemporary Families Study examined maternal mental health in both homosexual and heterosexual women (Fulcher et al., 2002). These researchers, however, utilized a convenience sample, which consisted of predominantly Caucasian, well-educated and wealthy participants, which are characteristics that can protect against depression (Ertel et al., 2011). The researchers also indicated that the children of lesbian mothers reported significantly more contact with non-familial adults than the children of heterosexual mothers. This finding suggests that these lesbian women had larger support systems, which potentially buffered them against depression.

The San Francisco Bay Area Families Study found no significant maternal mental health problems in a sample of 37 families (Patterson, 2001). However, they did not include a heterosexual comparison group. Without a comparison group, it is difficult to make accurate judgments about outcome correlations between heterosexual and homosexual mothers. Furthermore, over $90 \%$ of the sample was Caucasian and most possessed the protective characteristics of higher education and affluence (Ertel et al., 2011). Finally, the small, geographically homogeneous sample was a significant limitation, preventing the detection of a true difference and generalizability of findings.

The National Lesbian Family Study was a longitudinal study that followed lesbian families with a child conceived by donor insemination (Gartrell et al., 2000). This inclusion requirement alone may have biased study results since it is not known how donor insemination could affect study outcomes. In addition, the study only measured mental health on one criterion: whether or not women had sought counseling. Although this may reveal some information about 
mental health, it does not detail depressive symptomology or its relationship to lesbian motherhood. Including additional measures of depression would have likely provided a better indication of maternal mental health.

The Avon Longitudinal Study of Parents and Children was an extensive study that included a representative sample of lesbian mothers (Golombok et al., 2003). Results indicated that lesbian mothers were more likely to seek psychological treatment than heterosexual mothers were, but no more likely to endorse symptoms of depression. Although it is not known why these mothers sought treatment, seeking help is generally an indication of impairment. Consequently, further investigation into this finding is necessary to determine if it is predictive of depression. Caution must be taken furthermore because this study was conducted in the London. Lesbian, gay, bisexual and transgender (LGBT) individuals in the United Kingdom enjoy more rights and benefits than those in the United States. As a result, although there may be similarities, this is not an equal comparison and researchers may discover different outcomes if the study were to be conducted in the US.

Ross et al. (2007) examined perinatal depression among lesbian and bisexual women. They included a heterosexual comparison group but the sample was burdened by privileged demographics, geographic conformity, and a small sample size, similar to the studies reviewed above. Nevertheless, they found higher mean depression scores among the lesbian and bisexual mothers and concluded that although additional research is necessary, lesbian and bisexual mothers may have higher rates of depression than heterosexual mothers do.

Shapiro et al. (2009) conducted a study with lesbian and heterosexual mothers in the United States and Canada to examine how legal and social status affects depression. These researchers included Canadian lesbian mothers, a comparison group of minority status that is not 
associated with the same forms of discrimination as in the US. This provided a unique comparison group designed to allow evaluation of the effect of discrimination on mental health. They found that lesbian mothers in the US had higher rates of depression. Thus, depression may have different causal factors when unique risk factors are involved.

Most of the studies reviewed have serious limitations. Many lack a comparison group and do not include a diverse or representative sample; cross-sectional designs and ill-suited instruments further inhibit generalizability of findings. Nevertheless, all of the six reviewed studies have contributed invaluable information to lesbian health and wellness. Some research was driven by legal needs, to determine if lesbians were fit to be mothers; now, data indicate that children of lesbians are well adjusted and lesbian mothers do not present a danger to their children (Fitzgerald, 1999; Golombok et al., 2003; Tasker \& Golombok, 1995). Thus, the need for research has changed. We now need to explore if, when, and why depression affects lesbian mothers. Researchers need to examine if factors such as social support, general stress, and minority stress influence rates of depression among lesbian mothers. 


\subsection{METHOD}

The Relationships And Depression In Childbearing LEsbian (RADICLE) Moms Study was developed to explore depression and minority stress. The first aim of the study was to determine the prevalence rate of depression in a sample of self-identified lesbian women with at least one child less than 18 years of age. We hypothesized that lesbian mothers would experience higher rates of depressive symptoms than reported among presumed heterosexual mothers. In addition, we hypothesized that lesbian mothers with at least one child who is birth to 12 months of age would experience higher rates of depressive symptoms than lesbian mothers would without a child who is $0-12$ months of age. The second aim of the study was to investigate minority stress and determine if higher levels of social support reduce the effects of gay stress on depression symptoms. We hypothesized that social support would protect lesbian mothers from the negative effects of gay stress thereby reducing depressive symptoms. This analysis was guided by the minority stress model (Meyer, 2003).

The minority stress model predicts that minority stress can negatively affect psychological health but social support can mediate those effects (Meyer, 2003). Therefore, following this model will allow us to examine if there is a relationship between minority stress, social support, and maternal depression. Minority stress has been defined as “. . . culturally sanctioned, categorically ascribed inferior status, social prejudice and discrimination, the impact of these environmental forces on psychological well-being, and consequent readjustment or 
adaptation” (Brooks, 1981, p. 107). In this study, we classified gay stress as the source of minority stress, as research indicates they are independent stressors (Lewis et al., 2003).

\subsection{PARTICIPANTS}

In order to participate in this study, women had to be at least 18 years of age, have children living in the household, and identify as lesbian or gay, or have sex with women only. Bisexual women were not specifically targeted because research indicates that individuals who are bisexual often suffer from higher rates of depression, anxiety, and general stress than individuals who are homosexual or heterosexual; furthermore, they report less social support and poor integration into the gay community (Davis \& Wright, 2001; Dobinson, MacDonnell, Hampson, Clipsham, \& Chow, 2005; Jorm, Korten, Rodgers, Jacomb, \& Christensen, 2002). One-hundredsixty-nine individuals responded; of them, 131 met criteria for study participation (See APPENDIX A for a flow chart of sample reduction to identify lesbian mothers).

\subsection{RECRUITMENT}

\subsubsection{Mailed Recruitment}

Recruitment packets included detailed information about the study on University of Pittsburgh letterhead (see APPENDIX B for letter body) and a color flyer (see APPENDIX C). The flyer 
had tabs at the bottom for participants to detach; the tabs included the study name and the web address. Recruitment packets were mailed to 406 businesses, organizations, and professionals in the towns, cities, and boroughs of Hampshire County, Massachusetts; Windham County, Vermont; DeKalb County, Georgia; and Tompkins County, New York. These counties were chosen because, according to Census data, they are among the top US counties with a high percentage of lesbian residents (Gates \& Ost, 2004). Furthermore, Massachusettes and Vermont had marriage equality, whereas, Georgia and New York did not. During the study period, however, New York passed marriage equality. Nevertheless, zip code data indicated that participants from all over the country and one from outside of the country took part in the study so there was little utility in comparing data from Massachusettes and Vermont to Georgia and New York (See APPENDIX D for a map of participant zip codes). Limited resources restricted the study's range, therefore, in order to obtain a significant sample size, the mailed recruitment was concentrated to these areas.

The mailing was conducted during the month of May 2011. Places that specifically cater to or serve the LGBT community were initially identified for the mailing. After those were exhausted, libraries, community centers, childcare centers, free-care clinics, midwifery and parenting services, obstetric/gynecological offices, newspapers, WIC offices, colleges and universities, health departments, LGBT-friendly religious organizations, coffee shops and restaurants were targeted. Twenty-nine packets were returned by the post office, labeled as undeliverable. 


\subsubsection{Emailed and Online Recruitment}

In order to save on postal expenses, 321 additional professionals, business, and organizations that serve the counties were sent a recruitment packet by e-mail. Ninty-nine follow-up reponses were received, nearly 100\% were positive and indicated that the recipient would hang the flyer or include it in their next e-newsletter or e-blast.

A RADICLE Moms study Facebook page was created and advertisement space was purchased on Facebook (http://www.facebook.com/). Filters were set so the advertisment would target parents who were between the ages of 18 and 60 years. The advertisement included the name of the study, a color picture, and a 20 word description (see APPENDIX E). The estimated reach was 26.3 million people; it was displayed 532,005 times. The advertisement was clicked on 109 times, however, it was not possible to determine if those clicks resulted in a completed survey. On average, the price of each click was one dollar and cost prohibitive for this project. As such, it was only displayed from June to September 2011.

In addition to many newsletters, Internet forums, online classified advertisements and newspapers, Bay Windows, the largest provider of LGBT news in New England, placed a study advertisement banner on their website free of cost (Bay Windows, 2012). Individuals who clicked the banner were taken to the consent page of the study. The banner was very effective for recruitment; $17 \%$ of participants reported learning about the study through the banner advertisement. 


\subsection{PROCEDURE}

This survey, available through the SurveyMonkey website (http://www.surveymonkey.com/home/) from May 5, 2011 through December 31, 2011, was anonymous and cross-sectional. Previous research has demonstrated the effectiveness of utilizing online surveys to collect information from stigmatized populations (Andrews, Nonnecke, \& Preece, 2003; Klein, Lambing, Moskowitz, Washington, \& Gilbert, 2010; Marcus, Schmidt, Hamouda, \& Bochow, 2009). Furthermore, an online survey eliminated the need for a centralized location, which allowed us to reach a larger segment of the population. This study was approved by the University of Pittsburgh’s institutional review board (\#PRO11030172).

When prospective participants logged onto the survey site, they were given information about the study; specifically, they were informed of the risks, benefits, confidentiality of data, and contact information of the researchers. They were also told that they would not be compensated for their participation. If they chose to proceed, they were presented with three screening questions. The screening questions asked if they were at least 18 years of age, had at least one child living in the household, and identified as lesbian or gay, or as having sex with women only. Individuals who satisfied the screening requirements were invited to complete the survey, those who did not satisfy the screening requirements were not permitted to view or complete the survey. A SurveyMonkey control feature prevented individuals from accessing the site after they were disqualified or had submitted the survey. 


\subsection{MEASURES}

In addition to questions about basic demographic information, participants were given a series of standardized instruments. The questionnaires were selected based on their published high validity and reliability scales.

\subsubsection{Demographic Information}

Participants were asked for their age, race/ethnicity, highest level of education, employment status, income, and physical health status. They were also asked if they were currently in a relationship and if so, the longevity of that relationship. Participants were additionally asked for the number, age, and sex of each child; if the child was conceived while in heterosexual or homosexual relationship; and if the child was biological, adopted or her partner's child. In order to evaluate a history of depression, participants were asked if they have ever been diagnosed or treated for depression from a health care professional, and if one of their first-degree relatives had ever been diagnosis or treated for depression. Finally, for tracking purposes, participants were asked for their zip code, and how they learned about the study (see APPENDIX D for a map of participant zip codes. Maps were created using the website http://batchgeo.com/).

\subsubsection{Social Support}

Social support plays a significant role in health for pregnant women (Blanchard, Hodgson, Gunn, Jesse, \& White, 2009; Leahy-Warren et al., 2012; Seguin, Potvin, St-Denis, Loiselle, 1995). Social support is especially important for sexual minorities (Beals \& Peplau, 2005; McLaren, 
2009; Wayment \& Peplau, 1995). As a result, it was critical to assess the level of social support in the study sample. The Multidimensional Scale of Perceived Social Support (MSPSS) is a 12item questionnaire that utilizes a 7-point Likert scale with a subscale for family, friends, and significant other (Zimet, Dahlem, Zimet, \& Farley, 1988). Zimet et al. (1988) labels a romantic partner as a significant other, rather than spouse, indicating that this is a suitable instrument for sexual minorities. Higher scores on the MSPSS indicate greater social support. Psychometric properties were demonstrated by Zimet et al. (1988): Coefficient alpha reliability for the family subscale was 0.87 , reliability for the friends subscale was 0.85 , and reliability for the significant other subscale was 0.91 . Internal reliability and validity were also confirmed by research that included a sample of pregnant women (Zimet, Powell, Farley, Werkman, \& Berkoff, 1990).

\subsubsection{Depression}

The shortened form of the Center for Epidemiologic Studies Depression Scale (CES-D) was chosen as a measure of depression symptoms (Cole, Rabin, Smith, \& Kaufman, 2004; Radloff, 1977). The short form includes ten questions, instead of 20 as in the original version. The short form significanlty reduced the number of questions that the participants had to answer, a critical factor to consider when participants are not compensated. Scores range from zero to 30; a score of ten or more is generally recognized as a cut point for clinically significant number of depressive symptoms (Andresen, Malmgren, \& Carter, 1994; Smarr, 2003). Cronbach’s alpha for this form is 0.75 (Cole et al., 2004). The CES-D has been successfully used with other pregnant 
(Breedlove \& Fryzelka, 2011), childbearing (Azur, 2007), and LGB women (Balsam, Lehavot, Beadnell, \& Circo, 2010) and therefore the preferred screening instrument.

\subsubsection{Gay Stress}

The Measure of Gay Stress (MOGS) was develped to examine minority stress experienced by gay men and lesbian women (Lewis, Derlega, Berndt, Morris, \& Rose, 2001). MOGS is a 60item questionnaire that examines stress in the following areas: family reactions, family and partner, general discrimination, HIV/AIDS, misunderstanding, sexual orientation conflict, violence, friends and family visibility, public visibility, and work discrimination. The questions asked about HIV/AIDS were eliminated due to time restrictions and their limited utility for this project. Higher scores indicate higher levels of gay stress. Relability for the coefficient is strong and ranges from 0.72 to 0.90 (Lewis et al., 2001).

\subsubsection{General Stress}

In order to differentiate between minority stress and general stress, the Perceived Stress Scale Short (PSS-4) was administered (Cohen, Kamarck, \& Mermelstein, 1983). The PSS-4 contains four items, which are rated on a five-point Likert scale. The PSS-4 is significantly reduced from the orginal 14 items, thus, saving time for the participants. Higher scores indicate a higher level of percieved stress. The reliability coefficient for this instrument is 0.72 (Cohen et al., 1983). 


\subsection{RESULTS}

A frequency analysis, descriptive analysis, correlation analysis, and multiple linear regression analysis were conducted. Frequency statistics for participants' demographic characteristics are listed in Table 1. Descriptive statistics, including mean, standard deviation, and range are shown in Table 2. Complete data for the CES-D was obtained from 95 participants. One participant with missing data, however, reported a significant number of depressive symptoms and was included in the analysis. Only participants who answered at least three questions on the PSS-4, at least 47 questions on the MOGS, and at least 11 questions on the MSPSS were included in the analyses; mean substitution was used for missing data (Raaijmakers, 1999). The prevalence rate of clinical depression for this study was 8.4\%. Fifteen participants reported having a child aged birth to 12 months. Results indicate that none of these participants were suffering from clinically significant levels of postpartum depression.

Table 1: Participants' Demographic Characteristics as a Percentage of Sample

\begin{tabular}{ccc}
\hline & Variable & $\begin{array}{c}\text { All Participants } \\
(\mathrm{n}=115)\end{array}$ \\
\hline Age & & \\
& $18-24$ & $3.5 \%$ \\
$25-30$ & $7.0 \%$ \\
$31-40$ & $36.5 \%$ \\
$41-50$ & $38.3 \%$ \\
$51+$ & $14.8 \%$
\end{tabular}


Table 1 Continued

Race

American Indian or Alaska Native $\quad 1.7 \%$

Asian $2.6 \%$

African-American $\quad 3.5 \%$

Caucasian or White $\quad 92.2 \%$

Spanish, Hispanic, or Latino 2.6\%

Education

High school/GED $\quad 1.7 \%$

More than high school $\quad 18.3 \%$

College degree $\quad 25.2 \%$

Master's, Professional, Doctoral degree $\quad 54.8 \%$

Income

Under $\$ 15,000 \quad 3.5 \%$

$\$ 15,000-\$ 24,999 \quad 6.1 \%$

$\$ 25,000-\$ 34,999 \quad 11.3 \%$

$\$ 35,000-\$ 49,999 \quad 14.8 \%$

$\$ 50,000-\$ 74,999 \quad 23.5 \%$

$\$ 75,000-\$ 99,999 \quad 14.8 \%$

$\$ 100,000$ and over $\quad 23.5 \%$

Relationship status

Married

$46.1 \%$

Committed relationship $\quad 40.9 \%$

Dating $\quad 1.7 \%$

Single $\quad 11.3 \%$

Length of current relationship

Less than 6 months $\quad 2.6 \%$

6-12 months $\quad 4.3 \%$

$1-5$ years $24.3 \%$

6-10 years $17.4 \%$

More than 10 years $\quad 40.0 \%$

Employment status

Unemployed $\quad 3.5 \%$

Employed Part-time $\quad 18.2 \%$

Employed Full-time $\quad 68.7 \%$

Part-time Student $\quad 2.6 \%$

Full-time Student $\quad 2.6 \%$

Homemaker $\quad 13.0 \%$ 
Table 1 Continued

Physical health

Excellent

$29.6 \%$

Very good

$47.0 \%$

Good

$20.9 \%$

Fair

$1.7 \%$

Poor

$0.9 \%$

Personal depression history

$39.1 \%$

Familial depression history

$45.2 \%$

Unsure

$6.1 \%$

Gender of child

Girl

$56.8 \%$

Age of child

0-12 months

$8.7 \%$

1-4 years

$29.1 \%$

5-12 years

$43.6 \%$

13-17 years

$18.6 \%$

Child's relationship to mother

Biological

$54.1 \%$

Adopted

$26.0 \%$

Partner's child

$18.5 \%$

Relative's child

$1.4 \%$

Child conceived in

Heterosexual relationship $\quad 29.7 \%$

Same-sex relationship $\quad 70.3 \%$

Table 2: Measures of Stress among Lesbian Mothers (Means, SD, Range)

\begin{tabular}{lllll}
\hline Variable & $\mathrm{n}$ & $\mathrm{M}$ & $\mathrm{SD}$ & Range \\
\hline & & & & \\
CES-D & 95 & 4.40 & 4.21 & $0-18$ \\
PSS-4 & 115 & 4.56 & 2.94 & $0-14$ \\
MOGS & 107 & 26.78 & 23.65 & $0-119$ \\
MSPSS & 113 & 69.19 & 12.30 & $24-84$
\end{tabular}


Correlations between the variables were examined and are listed in Table 3. Social support was negatively correlated to gay stress $r(82)=-.40, p<.001$, depressive symptoms, $r(82)=-.41, p<.001$, and general stress $r(82)=-.30, p=.003$. Depressive symptoms were positively correlated to general stress $r(82)=.65, p<.001$, and gay stress, $r(82)=.27, p=.007$. Gay stress was also positively correlated to general stress $r(82)=.19, p=.044$.

Table 3: Correlations for Measures of Stress among Lesbian Mothers

\begin{tabular}{lllll}
\hline Measure & 1 & 2 & 3 & 4 \\
\hline 1. PSS-4 & --- & $-.30^{* *}$ & $.19^{*}$ & $.65^{* * *}$ \\
2. MSPSS & & --- & $-.40^{* * *}$ & $-.41^{* * *}$ \\
3. MOGS & & --- & $.27 * *$ \\
4. CES-D & & & --- \\
\hline
\end{tabular}

${ }^{*} \mathrm{p}<.05 ; * * \mathrm{p}<.01 ; * * * \mathrm{p}<.001$

Multiple linear regression analysis was used to examine the effect of general stress, gay stress, and social support on depressive symptoms. Due to the possibility of confounding factors, we controlled for age, income, educational attainment, employment status, health status, personal history of depression, familial history of depression, relationship status and length of relationship. Race was not included in the model since the sample included little racial variability. Responses of “unsure” for familial history of depression were coded as 0.5, although the model was unchanged if they were included with either the "yes" or "no" responses. The overall model was significant, $\mathrm{R}^{2}=.550, \mathrm{~F}(17,66)=4.74, \mathrm{p}<.001$.

Due to the high degree of correlation between MOGS, MSPSS, and PSS-4, each was examined in a separate regression model, controlling for the demographic factors listed above. 
Gay stress significantly predicted depression symptoms, $\mathrm{b}=.05, t(69)=2.40, p=.019$. Gay stress also explained a significant proportion of variance in depression symptoms, $R^{2}=.34, F(15$, $69)=2.32, p=.010$. Social support significantly predicted depression symptoms, $\mathrm{b}=-.15, t(75)$ $=-3.93, p<.001$, and explained a significant proportion of variance in depression symptoms, $R^{2}$ $=.41, F(15,75)=3.44, p<.001$. General stress also significantly predicted depression symptoms, $\mathrm{b}=.80, t(76)=6.00, p<.001$, and explained a significant proportion of variance, $R^{2}$ $=.51 F(15,76)=5.36, p<.001$. None of the demographic factors for which we controlled were statistically significant in any of the models.

Stepwise regression analysis was also conducted and results indicated that after controlling for demographic factors, general stress was the most significant predictor of depressive symptoms, $\mathrm{b}=.85, t(68)=5.61, p<.001 ; R^{2}=.51, F(1,68)=31.44, p<.001$. After controlling for demographic factors and general stress, social support was the next and final significant predictor of depressive symptoms, $\mathrm{b}=-.09, t(67)=-2.33, p=.023 ; R^{2}=.55, F(1,67)$ $=5.43, p=.023$. 


\subsection{DISCUSSION}

Researchers have not determined the risk or prevalence of postpartum depression (PPD) among lesbian women (Ross, 2005) nor identified theories or treatment for maternal depression among lesbian women. If, when, and why depression affects lesbian mothers needs to be examined, once known, maternal, partner, and child morbidity may decrease.

The first aim of this study was to determine the prevalence rate of depression in a sample of self-identified lesbian women with at least one child less than 18 years of age. We hypothesized that lesbian mothers would experience higher rates of depressive symptoms than reported among presumed heterosexual mothers. The second aim was to investigate minority stress and determine if higher levels of social support reduce the effects of gay stress on depression symptoms. We hypothesized that social support would protect lesbian mothers from the negative effects of gay stress thereby reducing depressive symptoms.

In this study, $8.4 \%$ of participants endorsed sufficient symptoms to indicate a current episode of clinical depression. The national rate of depression for US women varies from 2.6\% to $13.9 \%$, depending on age and location (Substance Abuse and Mental Health Services Administration, 2012). Additional research indicates that the rate for US mothers is 10.2\% (Ertel et al., 2011). Ertel et al. (2011) found that the rate varied considerably among the sample; of 
note, being aged 35 years or more, having a college degree, being married, having full-time employment, and having the highest income significantly reduced the rates of depression.

The depression rate for this sample of lesbian mothers is similar to rates for US women and mothers. Since depression is an enormous public health burden, this finding exemplifies the need for future research and treatment targeting this population. The majority of the women in this study were older and enjoyed high incomes, a college education, and full-time employment, which according to Ertel et al. (2011), were among the characteristics of women who reported the lowest levels of depression in their research with US mothers. This suggests that lesbian mothers at large may actually experience higher rates of depressive symptoms. Nevertheless, with nearly $10 \%$ of the sample experiencing an episode of clinical depression in the past week, additional research with lesbian mothers is critical.

An additional aim of this study was to examine postpartum depression. However, only fifteen participants reported having a child aged birth to 12 months. Although results indicate that none of these participants were suffering from clinically significant levels of postpartum depression, the sample is too small to draw meaningful conclusions.

An important finding of this study was that almost $40 \%$ of the participants reported a previous diagnosis of major depressive disorder. The lifetime prevalence rate for US women is 20.7\% (CDC, 2011). This survey did not collect information about the age that the women were diagnosed so it is unknown if the women were childbearing at the time of the diagnosis. Regardless, this finding indicates the dire need to target lesbian women with interventions to reduce depression.

The second aim of the study was to investigate minority stress and determine if higher levels of social support reduce the effects of gay stress on depression symptoms. We 
hypothesized that social support would protect lesbian mothers from the negative effects of gay stress thereby reducing depressive symptoms. A correlation analysis indicated that women who reported lower levels of social support reported higher levels of gay stress, depressive symptoms, and general stress. Social support independently predicted depressive symptoms when demographic characteristics were included in linear and stepwise regression analyses. This finding is not surprising and is supported by previous research that identified low social support as a significant risk factor for poor health outcomes (Beals \& Peplau, 2005; Blanchard et al., 2009; Seguin et al., 1995; Wayment \& Peplau, 1995). It signifies the importance of social support in this minority population and suggests that increasing social support alone may decrease depressive symptoms or the prevalence of gay stress.

Correlation analyses indicated that women who reported higher levels of general stress experienced lower levels of social support and higher levels of depressive symptoms and gay stress. When demographic factors were included, general stress independently predicted depression in linear and stepwise regression analysis. These results are expected and correspond with previous research (McFarlane, et al., 2005; Meyer \& Paul, 2011; Ross, 2005; Trettin et al., 2006). Although additional supporting evidence is needed, these findings suggest that targeting lesbian mothers with general stress reduction interventions may decrease their level of depression symptoms.

Correlation analysis indicated that women who reported higher levels of gay stress reported lower levels of social support as well as higher levels of depressive symptoms and general stress, which agrees with the minority stress model (Meyer, 2003). When demographic factors were included, gay stress was independently significant in linear regression analysis to predict depression. Gay stress, however, was not a significant predictor of depression in the 
stepwise regression analysis. Thus, although this study has limitations that prevent generalizability, results of the stepwise regression analysis provides evidence that the minority stress model may need to be adapted or perhaps discarded to understand depression more fully among lesbian mothers. As a result, not only is additional research needed to test this model but new theory is also needed to guide future research. Consequently, if and when evidence-based theories successfully predict depression among lesbian mothers, interventions can be developed to target and reduce depression symptoms among mothers.

\subsection{LIMITATIONS}

This study has a number of limitations. A primary limitation is that the participants' identities and eligibility could not be verified. Additional limitations include sampling bias, selection bias, volunteer bias, and measurement bias. Also, limitations result from the lack of a comparison group, lack of geographic diversity, and the possibility that other confounding factors unknowingly affected the results, including the possible impact of participation by the timing of Hurricane Irene.

Participants were recruited anonymously and on-line. Without the ability to verify identity, it is not possible to confirm eligibility of the participants or the accuracy of their responses. While it is possible that ineligible individuals completed the survey, without financial compensation there was little motivation to do so. Furthermore, the survey included three screening criteria and required 15-20 minutes to complete, thus, due to the lack of incentive, it is not likely that ineligible individuals would have taken the time to complete it. 
The majority of the sample was Caucasian, well educated, employed full-time, had household incomes in the higher income brackets, and were 31 years or older, thus indicating sampling bias and a non-representative sample of lesbian mothers that may be suffering from depressive symptoms. Ertel et al. (2011) indicates that being at least 35 years of age, having a college degree, being married, being employed full-time, and having a high income were protective factors against depression. The majority of the participants in this study had most of these protective factors; thus, it is possible that these mothers experienced artificially lower rates of depressive symptoms than did women of the national average.

Sampling bias may have also been present since participants learned about this study by seeing a flyer at a local business, organization, or professional; by seeing an advertisement in an LGBT newsletter or on Facebook; or by hearing about it from a friend, religious leader, or coworker. Most of these recruitment sources indicate social connections and/or involvement in the LGBT community. Thus, these participants are likely to enjoy larger amounts of social support than others who are more isolated or lacking community involvement. Consequently, these recruitment methods may have missed a large and important portion of the target population.

While every effort was made to recruit diverse women, selection bias may have affected the sample. Recruitment flyers were sent to hundreds of business and organizations of varied demographics, however, the flyer frequently had to be approved by higher management or the board of directors, thus the final distribution decision was theirs. Organizations and businesses that did not specifically cater to the LGBT population may not have believed that the survey suited their organization's mission. Furthermore, the stigma and fear of reprisal attached to the status of sexual minorities may have prevented some individuals from displaying the flyer. 
Volunteer bias may have affected the sample. There is a dearth of research with sexual minority samples. Highly educated women may be aware of this and thus be more willing to participate. Likewise, these participants may be researchers themselves and know the importance of expanding the research base with lesbian women. Furthermore, the lack of compensation may have been a deterrent for low-income participants. Individuals with lower incomes may have been experiencing financial and/or time constraints that prevented them from completing the survey.

Items from MOGS were mistakenly not randomized, thereby introducing measurement bias. The questions were categorized by family, friends, work, etc. Investigation of the questions provided no indication that the results would have been significantly different if randomized. Furthermore, retesting with a small sample did not change the results. Although it is not possible to determine if this error affected survey results, MOGS was the least significant predictor of depression symptoms; thus, if anything, the results were overly conservative. Additionally, the findings for social support and general stress were significant even if gay stress was removed from the analysis.

This study did not include a heterosexual comparison group. The rate of depression was compared to the national rates of depression, which was determined using different methods and instruments. However, due to the validity and reliability of most standard instruments, it is unlikely that these varied collection efforts significantly affected the results. Nationally reported rates of depression include all women, including sexual minorities; therefore, if these minorities have increased rates of depression, their inclusion may have artificially inflated the national average. Nevertheless, since the population of sexual minority women is small, this bias is likely to be insignificant. 
The lack of geographic diversity among the participants is also a limitation. The majority of the data were collected from residents of the East Coast; thus, those individuals may have unspecified risk or protective factors that significantly influenced the results. This and the small sample size indicate the need for a large, geographically diverse study population.

Additionally, unknown factors may have influenced participation or responses obtained from this study introducing unidentified confounding. For example, Hurricane Irene may have affected study participation and responses due to its significant damage to the east coast in August of 2011. However, an examination of participation dates and zip codes indicates that only eight surveys were collected from the affected zip codes after the Hurricane ("List of,” 2011). Although it is not possible to determine if those participants were personally affected, the surveys were completed within four months of the Hurricane; thus, it seems unlikely that individuals directly affected would have completed an uncompensated survey. Furthermore, a regression analysis was conducted without the eight participants and there was no difference in the significance level of the model. It is also possible that the response rate was affected by Hurricane Irene. Twenty-four surveys were completed before the Hurricane in the affected zip codes, whereas only eight were completed afterward. However, recruitment efforts began in May 2011, thus, it is expected that participation would taper off as the areas became saturated with flyers; therefore, the effect of the Hurricane on the response rate was likely minimal. 


\subsection{FUTURE RESEARCH DIRECTION}

Although only a portion of the study population endorsed evidence for a current major depressive episode, nearly $40 \%$ have a personal history, treatment, and/or diagnosis of depression from a health care provider. Since a personal history of depression is a risk factor for additional major depressive episodes (Solomon et al., 2005), effectively recognizing and treating depression in this minority population may help to reduce future morbidity and possibly mortality for the sufferer. In the next section, barriers for recognizing and treating depression will be explored and recommendations for future research will be proposed.

\subsection{BARRIERS TO IDENTIFYING AND TREATING DEPRESSION}

Barriers to identifying depression and developing treatment programs are widespread and exist on a national, organizational, and individual level. These barriers are common for many women and mothers; however, additional, unique barriers exist for lesbian women and mothers.

The federal government acts as a national barrier since it fails to recommend universal PPD and maternal mental health screenings (Santoro \& Peabody, 2010). Without a strong, united, national voice, identification, the most basic and easiest part of treatment, can be disjointed and maternal depression may remain undiagnosed and untreated. 
Lesbian women and mothers experience additional national barriers. The lack of federal benefits and marriage equality prevents LGBT individuals from domestic partner benefits and tax benefits. Program such as Consolidated Omnibus Budget Reconciliation Act (COBRA), Family Medical Leave Act (FMLA), Flexible Spending Accounts (FSA), and Health Savings Accounts (HSA) do not apply to couples in domestic partnerships (Human Rights Campaign, n.d.). Some employers, however, do provide some benefits to same-sex couples; nevertheless, the benefits package is often subject to taxes not imposed on heterosexual couples (Badgett, 2007). Regardless, in instances where individual employers provide same-sex partner benefits, some individuals report not using those benefits for fear of "coming out" at work (Coalition for Lesbian and Gay Rights in Ontario [CLGRO], 1997). As a result, lesbian women, especially homemakers, may not carry insurance or be financially able to pay for treatment (American College of Obstetricians and Gynecologists [ACOG], 2009; Austin \& Irwin, 2010).

There are multiple organizational barriers. In a qualitative study, a physician indicated that other conditions, such as diabetes, are more important to identify and treat than depression (Edge, 2010). Other physicians in the study indicated that they did not feel they had a clearly defined protocol or the education to accurately diagnosis depression. Furthermore, incongruent care and poor communication between physicians were cited as further complications for diagnosing and treating depression.

In addition to the organizational barriers that affect heterosexual women, many lesbian women experience discrimination from the medical community, which may significantly affect mental health diagnosis and treatment (ACOG, 2009; CLGRO, 1997; Steele, Ross Epstein, Strike, \& Goldfinger, 2008). Intake paperwork often fails to recognize same-sex relationships and clinical training often omits LGBT-specific issues (CLGRO, 1997). Consequently, research 
indicates that some lesbian women report anxiety in sharing their sexual orientation with their health care provider for fear that it may affect their care (CLGRO, 1997; McManus, Hunter, \& Renn, 2006.) Furthermore, some LGBT individuals avoid seeing physicians who are not specifically LGBT-friendly, which may cause delays in treatment or failure to receive specialty care due to a lack of providers (CLGRO, 1997).

A number of individual barriers affect the diagnosis and treatment of depression in women. During focus groups, one group of researchers found that many mothers did not feel comfortable talking to their doctors about their depressive symptoms (Heneghan, Mercer, \& DeLone, 2004). Some even feared that their doctor would report them to social services if they revealed the extent of their problems. Other women indicated that they did not know where to seek help or what treatment was available. On the other hand, women in a different study refused treatment, medication specifically, for fear of physical addiction or adverse health consequences for their breastfeeding infants (Turner, Sharp, Folkes, \& Chew-Graham, 2008).

Individual barriers unique to lesbian women are interrelated with national and organizational barriers. Two barriers are repeatedly reported. The first is that lesbian women often choose not to use health care services due to negative past experiences resulting from homophobia (ACOG, 2006; Austin \& Irwin, 2010; CLGRO, 1997; Hutchinson, Thompson, \& Cederbaum, 2006; McManus et al., 2006); the second is the financial burden of health care, usually due to the lack of health insurance (ACOG, 2006; Austin \& Irwin, 2010; CLGRO, 1997; Hutchinson et al., 2006; McManus et al., 2006). These barriers combined with those common to heterosexual women, such as lack of knowledge about illnesses and treatments (Heneghan et al., 2004), indicate that additional research and efforts targeting lesbian women is dire. 
Understanding barriers may allow programs to be adapted specifically for lesbian mothers. For example, the financial burden of treatment indicates the need for a low-cost intervention. Research indicates that online cognitive behavioral therapy (CBT) depression treatment programs are efficacious, cost-effective, and acceptable to users (Bowler et al., 2012; Carter, Bell, \& Colhoun, 2012; McCrone et al., 2004; Proudfoot et al., 2004). Some research has been conducted using online treatment programs with lesbian women and provides evidence that they may be a promising option for this population (van Brunt, 2009). Regardless, since lesbian women are at an increased risk of depression and the consequences of depression are widespread, additional theories and research are essential. 


\subsection{CONCLUSION}

Strong evidence suggests that lesbian women suffer from greater rates of depression than do heterosexual women (Bradford \& Ryan, 1988; Gilman et al., 2001; Harrison, 1996; Sorensen \& Roberts, 1997; White \& Levinson, 1995). However, existing research offers conflicting findings about depression outcomes. Much research indicates that lesbian mothers are at no higher risk for developing depression or poor mental health outcomes than their heterosexual counterparts (Fulcher et al., 2002; Gartrell et al., 2000; Patterson, 2001). These findings, however, have limitations that do not account for unique risk factors that may influence the expression of depression in this population. Since depression affects morbidity of the patient and others, including partners and children (Ahlström et al., 2009; Bulloch et al., 2009; Campbell et al., 2009; Fanti \& Henrich, 2010; Ishaque, 2009; Santos et al., 2010), it is critical to know prevalence rates of depression, as well as unique risk and protective factors that may influence symptoms among lesbian mothers.

The first aim of the RADICLE Moms Study was to determine the prevalence rate of depression in a sample of self-identified lesbian women with at least one child less than 18 years of age. We hypothesized that lesbian mothers would experience higher rates of depressive symptoms than reported among presumed heterosexual mothers. One-hundred-thirty-one eligible participants completed an anonoymous Internet survey. Results indicate that $8.4 \%$ of the sample reported clinically significant levels of depressive symptoms. This rate is similar to that of US 
women and mothers. However, limitations of the sample such as privileged demographics suggest that women in the lesbian mother population at large may experience significantly higher rates of depressive symptoms. Regardless, nearly $40 \%$ of the participants reported a previous diagnosis of major depressive disorder, which is almost double that of the national average for US women (CDC, 2011).

The second aim of the study was to investigate minority stress and determine if higher levels of social support reduce the effects of gay stress on depression symptoms. We hypothesized that social support would protect lesbian mothers from the negative effects of gay stress thereby reducing depressive symptoms. Correlation analysis indicated that women who reported higher levels of social support did have lower levels of gay stress and depression symptoms. Multiple regression analysis provided an independent link between gay stress and depression as well as social support and depression. A high level of general stress was also a significant predictor of depressive symptoms. Although additional supporting evidence is needed, these finding suggest that targeting lesbian mothers with interventions to decrease general stress or gay stress or to increase social support may reduce depression symptoms.

As illustrated with this study, understanding the causes of depression can be very challenging; however, treating it can be similarly difficult. These challenges stem from many national, organizational, and individual level barriers, some that are unique to lesbian women. Integrating knowledge of these barriers with the findings from the RADICLE Moms Study indicates that an online program may be a possible treatment option for lesbian mothers suffering from depression. Other research has already begun exploring this option (van Brunt, 2009). LGBT-adapted online programs may overcome the financial burden of treatment, provide a supportive community for mothers, and decrease gay stress experienced from the medical 
community. Regardless, in order to reduce negative health outcomes for lesbian mothers and their families, further research and theory development on the risk and protective factors of depression is critical. 


\section{APPENDIX A}

\section{FLOW CHART OF SAMPLE REDUCTION TO IDENTIFY LESBIAN MOTHERS}

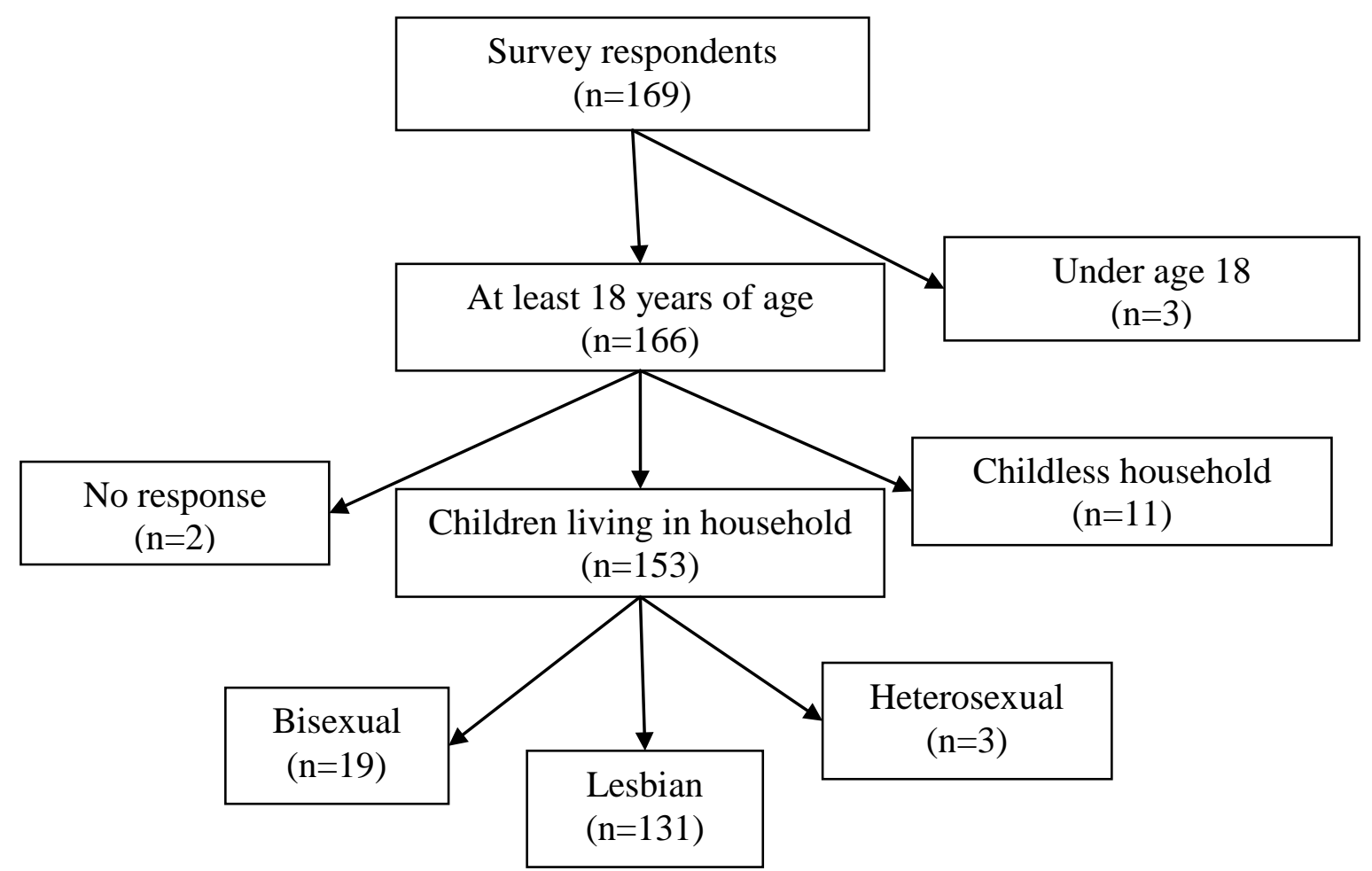

Figure 1: Flow Chart of Sample Reduction to Identify Lesbian Mothers 


\section{APPENDIX B}

\section{BODY OF RECRUITMENT LETTER}

I am a graduate student at the University of Pittsburgh, working under the mentorship of Drs. Nina Markovic and Beth Nolan. For my thesis, I am conducting The RADICLE Moms Study, a research study to learn more about mood and social support among lesbian mothers. I am conducting the research in various parts of the country in order to obtain a representative sample. The study is a 10-15 minute anonymous online survey. I am recruiting lesbian women, ages 18 or older, who have a child under the age of 18. Participants will not receive payment for their time but participation is completely voluntary and confidential. No identifiable information is asked or recorded. Would you be able to post a flier or survey link in your church, on your website or include it in a newsletter, e-blast, listsrv, blog, mailing, or similar posting; or even send it to someone else who may be able to help? Little is known about lesbian mothers; I hope that this study will allow us to better understand lesbian motherhood and, in the future, develop support or treatment for mothers who need it. In order to be successful though, I need the largest sample possible. Your support and assistance would be greatly appreciated. Thank you! 
APPENDIX C

RECRUITMENT FLYER

\section{The RADICLE Moms Study}

A graduate student at the University of Pittsburgh is conducting a research study to learn more about mood and social support among lesbian mothers.

You are eligible for this research study if:

- You are 18 years or older and identify as lesbian

- Have a child who is under 18 years of age

You can be single, partnered, or married.

If you decide to take part in this study, you would have to fill out an online survey in which we would ask you:

- General background information

- Questions about your relationships, life experiences and mood

The study will take no more than 15 minutes and can be completed online at your convenience. You will not receive payment for this study. Your participation is voluntary and completely confidential. 
To take part in this research study and help us learn more about lesbian mothers, please visit https://www.surveymonkey.com/s/RADICLEmoms

The principal researcher for this study is Sherri Mosovsky who can be reached at radiclemomsstudy@yahoo.com

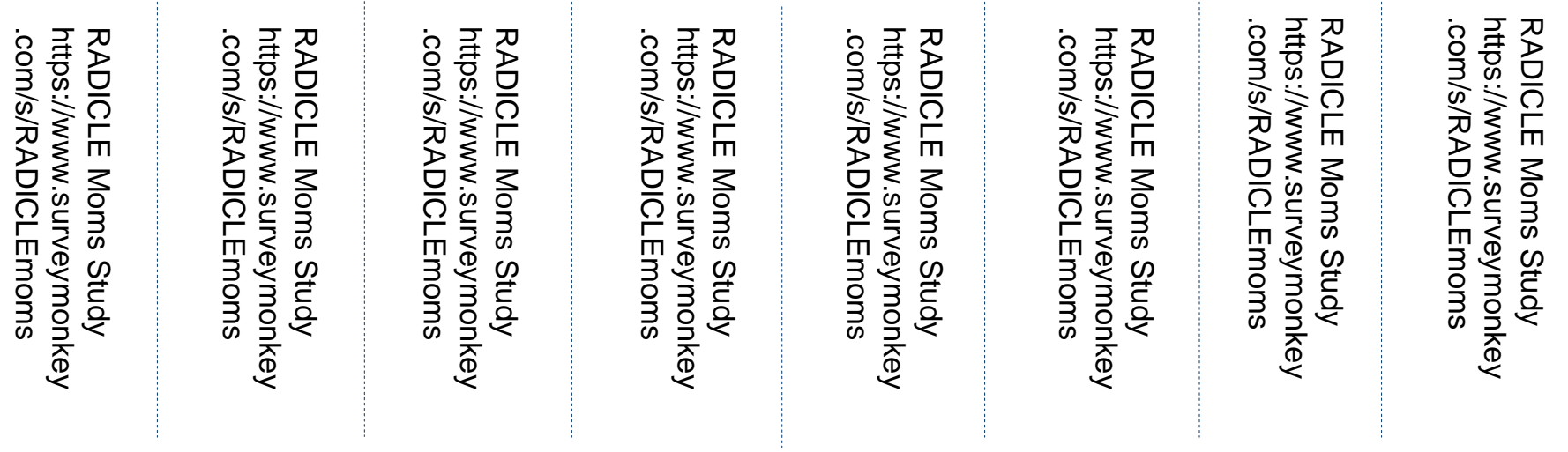




\section{APPENDIX D}

\section{ZIP CODE MAPS}
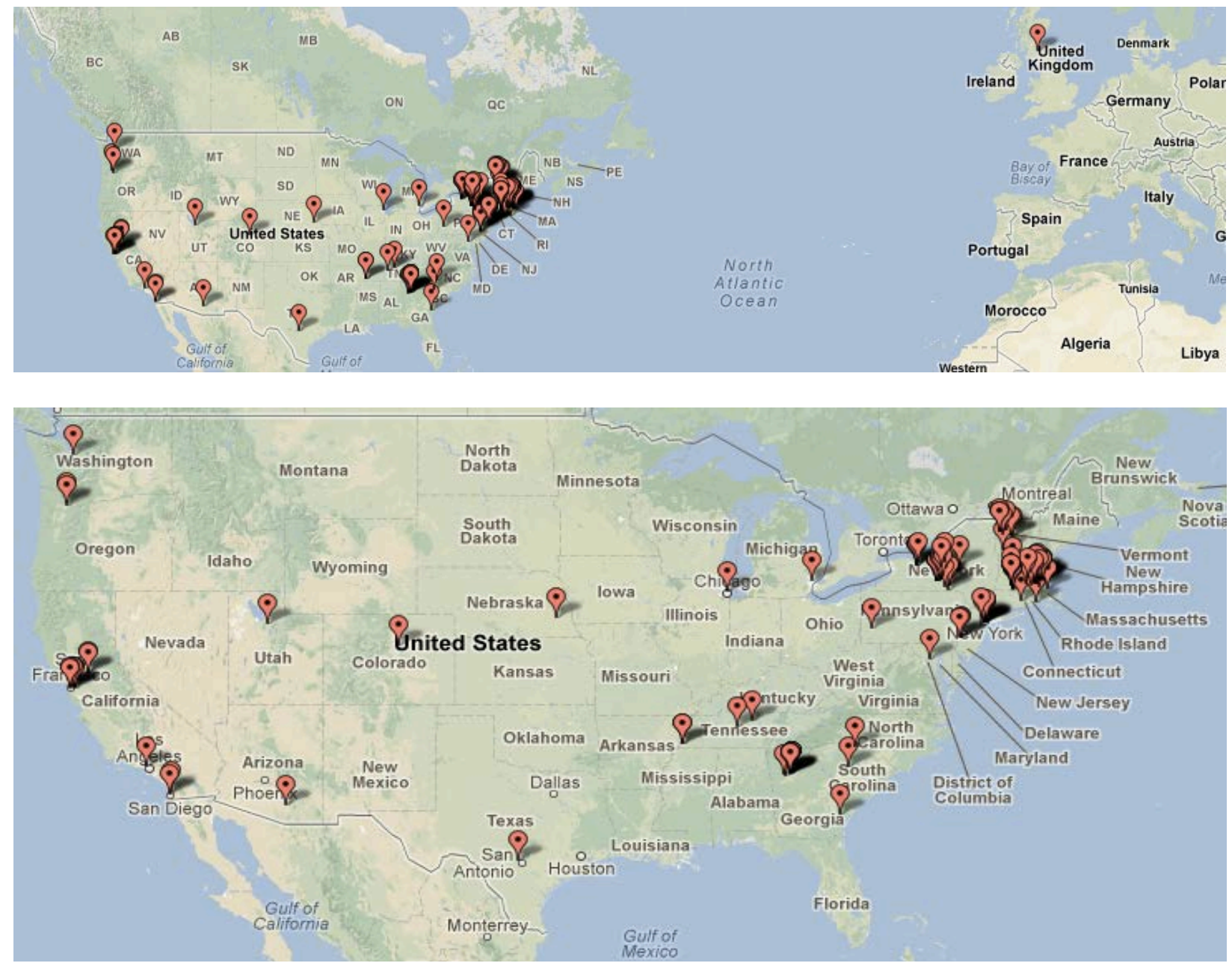

Source: http://batchgeo.com/

Figure 2: Maps of Participant Zip Codes 


\section{APPENDIX E}

\section{FACEBOOK ADVERTISEMENT}

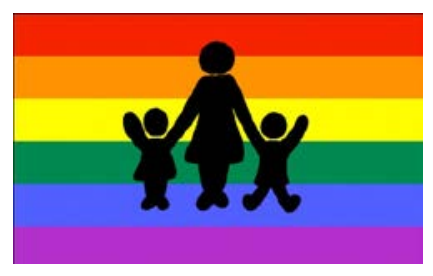

\section{The RADICLE Moms Study}

Lesbian Moms: Please

take our survey on mood

and social support for a

graduate student at the

University of Pittsburgh.

Figure 3: Advertisement Displayed on Facebook 


\section{BIBLIOGRAPHY}

Agency for Healthcare Research and Quality. (2000). Improving quality of care for people with depression. Translating research into practice. Fact sheet. (Publication No. 00-P020). Retrieved from http://www.ahrq.gov/research/deprqoc.htm

American College of Obstetricians and Gynecologists. (2009). ACOG Committee Opinion No. 428: Legal status: Health impact for lesbian couples. Obstetrics \& Gynecology, 113(2, Pt. 1), 469-472. Retrieved from doi:10.1097/AOG.0b013e3181993133

Andresen, E. M., Malmgren, J. A., Carter, W. B., \& Patrick, D. L. (1994). Screening for depression in well older adults: Evaluation of a short form of the CES-D (Center for Epidemiologic Studies Depression Scale). American Journal of Preventative Medicine, 10(2), 77-84. Retrieved from http://www.journals.elsevier.com/american-journal-ofpreventive-medicine/

Andrews, D., Nonnecke, B., \& Preece, J. (2003) Electronic survey methodology: A case study in reaching hard to involve Internet users. International Journal of Human-Computer Interaction, 16(2), 185-210. Retrieved from doi:10.1207/S15327590IJHC1602_04

Ahlström, B. H., Skärsäter, I., \& Danielson, E. (2009). Living with major depression: Experiences from families' perspectives. Scandinavian Journal of Caring Sciences, 23(2), 309-316. Retrieved from doi:10.1111/j.1471-6712.2008.00624.x

Austin, E. L., \& Irwin, J. A. (2010). Health behaviors and health care utilization of southern lesbians. Women's Health Issues, 20(3), 178-84. Retrieved from http://dx.doi.org/10.1016/j.whi.2010.01.002

Azur, M. J. (2007). The effects of maternal depression on child health and development. (Doctoral Dissertation). Retrieved from ProQuest Dissertations \& Theses. (3262379).

Badgett, L. (2007). Unequal taxes on equal benefits: The taxation of domestic partner benefits. Center for American Progress and Williams Institute. Retrieved from http://www.americanprogress.org/issues/civil-liberties/report/2007/12/03/3744/unequaltaxes-on-equal-benefits/

Balsam, K. F., Lehavot, K., Beadnell, B., \& Circo, E. (2010). Childhood abuse and mental health indicators among ethnically diverse lesbian, gay, and bisexual adults. Journal of 
Consulting and Clinical Psychology, 78(4), 459-468. Retrieved from

doi:10.1037/a0018661

Bay Windows. (2012). About Bay Windows. Retrieved from

http://www.baywindows.com/index.php?ch=pages\&id=12

Beals, K. P., \& Peplau, L. A. (2005). Identity support, identity devaluation, and wellbeing among lesbians. Psychology of Women Quarterly, 29, 140-148. Retrieved from

doi:10.1111/j.1471-6402.2005.00176.x

Blanchard, A., Hodgson, J., Gunn, W., Jesse, E., \& White, M. (2009). Understanding social support and the couple's relationship among women with depressive symptoms in pregnancy. Issues in Mental Health Nursing, 30(12), 764-776. Retrieved from doi:10.3109/01612840903225594

Bowler, J. O., Mackintosh, B., Dunn, B. D., Mathews, A., Dalgleish, T., \& Hoppitt, L. (epub 2012). A comparison of cognitive bias modification for interpretation and computerized cognitive behavior therapy: effects on anxiety, depression, attentional control, and interpretive bias. Journal of Consulting and Clinical Psychology, 80(6), 1021-33. Retrieved from doi:10.1037/a0029932

Bradford, J., \& Ryan, C. (1988). The national lesbian health care survey final report. Washington, DC: National Lesbian and Gay Health Foundation.

Breedlove, G., \& Fryzelka, D. (2011). Depression Screening During Pregnancy. Journal of Midwifery \& Women's Health, 56(1), 18-25. Retrieved from doi:10.1111/j.15422011.2010.00002.x

Brooks, V. R. (1981). Minority stress and lesbian women. Lexington, Massachusetts: DC Heath and Company.

Bulloch, A. G., Williams, J. V., Lavorato, D. H., \& Patten, S. B. (2009). The relationship between major depression and marital disruption is bidirectional. Depression \& Anxiety, 26(12), 1172-1177. Retrieved from doi:10.1002/da.20618

Campbell, S. B., Morgan-Lopez, A. A., Cox, M. J., \& McLoyd, V. C. (2009). A latent class analysis of maternal depressive symptoms over 12 years and offspring adjustment in adolescence. Journal of Abnormal Psychology, 118(3), 479-93. Retrieved from doi:10.1037/a0015923

Carter, F. A., Bell, C. J., \& Colhoun, H. C. (Epub 2013). Suitability and acceptability of computerised cognitive behaviour therapy for anxiety disorders in secondary care. Australian and New Zealand Journal of Psychiatry, 47(2), 142-152. Retrieved from doi:10.1177/0004867412461384

Centers for Disease Control and Prevention. (2011, September). Mental illness surveillance among adults in the United States. (Morbidity and Mortality Weekly Report, Supplement/Vol. 60). Retrieved from http://www.cdc.gov/mentalhealthsurveillance/ 
Coalition for Lesbian and Gay Rights in Ontario. (1997). Systems failure: A report on the experiences of sexual minorities in Ontario's health-care and social-services system. Toronto: Author.

Cochran, S. D. (2001). Emerging issues in research on lesbians' and gay men's mental health: Does sexual orientation really matter? The American Psychologist, 56, 929-947. Retrieved from http://www.apa.org/pubs/journals/amp/index.aspx

Cohen, S., Kamarck, T., \& Mermelstein, R. (1983). A global measure of perceived stress. Journal of Health and Social Behavior, 24, 385-396. Retrieved from http://www.asanet.org/journals/jhsb/jhsb.cfm

Cole, J. C., Rabin, A. S., Smith, T. L., \& Kaufman, A. S. (2004). Development and validation of a Rasch-derived CES-D short form. Psychological Assessment, 16(4), 360-372. Retrieved from http://www.apa.org/pubs/journals/pas/index.aspx

Crawford, I., McLeod, A., Zamboni, B. D., \& Jordan, M. B. (1999). Psychologists’ attitude toward gay and lesbian parenting. Professional Psychology: Research \& Practice, 30, 394-401. Retrieved from doi:10.1037/0735-7028.30.4.394

Davis, C., \& Wright, A. (2001). How well are we doing? A survey of the GLBT population of Ottawa. Ottawa: Pink Triangle Services.

Dobinson, C., MacDonnell, J., Hampson, E., Clipsham, J., \& Chow, K. (2005). Improving the access and quality of public health services for bisexuals. Journal of Bisexuality, 5(1), 3978. Retrieved from http://www.opha.on.ca/index.shtml

Edge, D. (2010). Falling through the net - black and minority ethnic women and perinatal mental healthcare: Health professionals' views. General Hospital Psychiatry, 32(1), 17-25. Retrieved from doi:10.1016/j.genhosppsych.2009.07.007

Ertel, K. A., Rich-Edwards, J. W., \& Koenen, K. C. (2011). Maternal depression in the United States: Nationally representative rates and risks. Journal of Women's Health 20, 16091617. Retrieved from doi:10.1089/jwh.2010.2657

Fanti, K. A., \& Henrich, C. C. (2010). Trajectories of pure and co-occurring internalizing and externalizing problems from age 2 to age 12: findings from the National Institute of Child Health and Human Development Study of Early Child Care. Developmental Psychology. 46(5), 1159-75. Retrieved from doi:10.1037/a0020659

Fitzgerald, B. (1999). Children of lesbian and gay parents. Marriage \& Family Review, 29(1), 57-75. Retrieved from doi:10.1300/J002v29n01_05

Frayne, J., Nguyen, T., \& Allen, S. (2009). Motherhood and mental illness: Part 1 - toward a general understanding. Australian Family Physician, 38(8), 594-600. Retrieved from http://www.racgp.org.au/afp 
Friedman, N. A. (1999). The experience of pregnancy for lesbian couples. (Doctoral Dissertation). Retrieved from ProQuest Dissertations \& Theses. (9903743.)

Fulcher, M., Sutfin, E. L., Chan, R. W., Scheib, J. E., \& Patterson, C. J. (2005). Lesbian mothers and their children: Findings from the Contemporary Families Study. In A. Omoto \& H. Kurtzman (Eds.), Recent Research on Sexual Orientation, Mental Health, and Substance Abuse (281 - 299). Washington, DC: American Psychological Association.

Gartrell, N., Banks, A., Hamilton, J., Reed, N., Bishop, H., \& Rodas, C. (1999). The National Lesbian Family Study: 2. Interviews with mothers of toddlers. American Journal of Orthopsychiatry, 69, 362-369. Retrieved from doi:10.1037/h0080410

Gartrell, N., Banks, A., Reed, N., Hamilton, J., Rodas, C., \& Deck, A. (2000). The National Lesbian Family Study: 3. Interviews with mothers of five-year-olds. American Journal of Orthopsychiatry, 70, 542-548. Retrieved from doi:10.1037/h0087823

Gates, G. J., Badgett, M. V., Macomber, J. E., \& Chambers, K. (2007). Adoption and foster care by gay and lesbian parents in the United States. Washington, DC: Urban Institute Press. Retrieved from http://www.urban.org/url.cfm?ID=411437

Gates, G. J., \& Ost, J. (2004). Gay \& lesbian atlas. Washington, DC: Urban Institute Press.

Gavin, N. I., Gaynes, B. N., Lohr, K. N., Meltzer-Brody, S., Gartlehner, G., \& Swinson, T. (2005). Perinatal depression: A systematic review of prevalence and incidence. Obstetrics \& Gynecology, 106, 1071-1083. Retrieved from doi:10.1097/01.AOG.0000183597.31630.db

Gilman, S. E., Cochran, S. D., Mays, V. M., Hughes, M., Ostrow, D., \& Kessler, R. C. (2001). Risk of psychiatric disorders among individuals reporting same-sex sexual partners in the National Comorbidity Survey. American Journal of Public Health, 91, 933-939.

Retrieved from http://ajph.aphapublications.org/

Golombok, S., Perry, B., Burston, A., Murray, C., Mooney-Somers, J., Stevens, M., \& Golding, J. (2003). Children with lesbian parents: A community study. Developmental Psychology, 39, 20-33. Retrieved from doi:10.1037//0012-1649.39.1.20

Harrison, A. E. (1996). Primary care of lesbian and gay patients: Educating ourselves and our students. Family Medicine, 28, 10-23. Retrieved from http://www.stfm.org/index.cfm

Heneghan, A. M., Mercer, M., \& DeLeone, N. L. (2004). Will mothers discuss parenting stress and depressive symptoms with their child's pediatrician? Pediatrics, 113(3 Pt 1), 460467. Retrieved from http://pediatrics.aappublications.org/

Human Rights Campaign. (n.d.). Federal laws impacting domestic partner benefits. Retrieved from http://www.hrc.org/resources/entry/federal-laws-impacting-domestic-partnerbenefits 
Hutchinson, M. K., Thompson, A. C., \& Cederbaum, J. A. (2006). Multisystem factors contributing to disparities in preventive health care among lesbian women. Journal of Obstetric, Gynecologic, \& Neonatal Nursing, 35(3), 393-402. Retrieved from doi:10.1111/j.1552-6909.2006.00054.x

Ishaque, S. (2009). Management of maternal depression to improve child health outcome. Journal of the College of Physicians \& Surgeons, 19(9), 601-612. Retrieved from doi:09.2009/JCPSP.601602

Jorm, A. F., Korten, A. E., Rodgers, B., Jacomb P. A., \& Christensen, H. (2002). Sexual orientation and mental health: Results from a community survey of young and middleaged adults. British Journal of Psychiatry, 180, 423-427. Retrieved from doi:10.1192/bjp.180.5.423

Khatib, Y., Bhui, K., \& Stansfeld, S. A. (2013). Does social support protect against depression \& psychological distress? Findings from the RELACHS study of East London adolescents. Journal of Adolescence. Advance online publication. Retrieved from doi:http://dx.doi.org/10.1016/j.adolescence.2013.01.001

Klein, H., Lambing, T. A., Moskowitz, D. A., Washington, T. A., \& Gilbert, L. K. (2010). Recommendations for performing Internet-based research on sensitive subject matter with "hidden” or difficult-to-reach populations. Journal of Gay \& Lesbian Social Services, 22(4), 371-398. Retrieved from doi:10.1080/10538720.2010.491742

Leahy-Warren, P., McCarthy, G., \& Corcoran, P. (2012). First-time mothers: Social support, maternal parental self-efficacy and postnatal depression. Journal of Clinical Nursing 21, 388-397. Retrieved from doi:10.1111/j.1365-2702.2011.03701.x

Lewis, R. J., Derlega, V. J., Berndt, A., Morris, L. M., \& Rose, S. (2001). An empirical analysis of stressors for gay men and lesbians. Journal of Homosexuality, 42(1), 63-88. Retrieved from doi:10.1300/J082v42n01_04

Lewis, R. J., Derlega, V. J., Griffin, J. L., \& Krowinski, A. C. (2003). Stressors for gay men and lesbians: Life stress, gay-related stress, stigma consciousness, and depressive symptoms. Journal of Social and Clinical Psychology, 22(6), 716-729. Retrieved from doi:10.1521/jscp.22.6.716.22932

List of counties and zip codes affected by Hurricane Irene. (2011). Retrieved from http://heuristically.wordpress.com/2011/09/01/list-of-counties-and-zip-codes-affected-byhurricane-irene/

Marcus, U., Schmidt, A. J., Hamouda, O., \& Bochow, M. (2009). Estimating the regional distribution of men who have sex with men (MSM) based on Internet surveys. BMC Public Health, 9, 180-191. Retrieved from doi:10.1186/1471-2458-9-180

McCrone, P., Knapp, M., Proudfoot, J., Ryden, C., Cavanagh, K., Shapiro, D. A.,...Tylee, A. (2004). Cost-effectiveness of computerised cognitive-behavioural therapy for anxiety and 
depression in primary care: Randomised controlled trial. British Journal of Psychiatry, 185, 55-62. Retrieved from doi:10.1192/bjp.185.1.55

McFarlane, A., Clark, C., Bryant R., Williams, L., Niaura, R., Paul, R.,...Gordon, E. (2005). The impact of early life stress on psychophysiological, personality and behavioral measures in 740 nonclinical subjects. Journal of Integrative Neuroscience, 4, 27-40. Retrieved from doi:10.1142/S0219635205000689

McLaren, S. (2009). Sense of belonging to the general and lesbian communities as predictors of depression among lesbians. Journal of Homosexuality, 56(1), 1-13. Retrieved from http://dx.doi.org/10.1080/00918360802551365

McManus, A. J., Hunter, L. P., \& Renn, H. (2006). Lesbian experiences and needs during childbirth: Guidance for health care providers. Journal of Obstetric, Gynecologic, \& Neonatal Nursing, 35(1), 13-23. Retrieved from doi: 10.1111/j.1552-6909.2006.00008.x

Meyer, D., \& Paul, R. (2011). A cross-national examination of marriage and early life stressors as correlates of depression, anxiety, and stress. The Family Journal, 19(3), 274-280. Retrieved from doi:10.1177/1066480711406678

Meyer, I. H. (2003). Prejudice, social stress, and mental health in lesbian, gay, and bisexual populations: Conceptual issues and research evidence. Psychological Bulletin, 129, 674697. Retrieved from doi:10.1037/0033-2909.129.5.674

O’Hanlan, K. A., Dibble, S. L., Hagan, H. J., \& Davids, R. (2004). Advocacy for women’s health should include lesbian health. Journal of Women's Health, 13, 227-234. Retrieved from http://www.liebertpub.com/overview/journal-of-womens-health/42/

O’Hara, M. W., \& Swain, A. M. (1996). Rates and risk of postpartum depression - a metaanalysis. International Review of Psychiatry, 8, 37-54. Retrieved from doi:10.3109/09540269609037816

Patterson, C. (2001). Families of the lesbian baby boom: Maternal mental health and child adjustment. Journal of Gay and Lesbian Psychotherapy, 4, 91-107. Retrieved from doi:10.1300/J236v04n03_07

Proudfoot, J., Ryden, C., Everitt, B., Shapiro, D. A., Goldberg, D., Mann, A.,...Gray, J. A. (2004). Clinical efficacy of computerised cognitive-behavioural therapy for anxiety and depression in primary care: Randomised controlled trial. British Journal of Psychiatry, 185, 46-54. Retrieved from doi:10.1192/bjp.185.1.46

Radloff, L. S. (1977). The CES-D: A self-report depression scale for research in the general population. Applied Psychological Measurement, 1(3), 385-401. Retrieved from doi:10.1177/014662167700100306

Raaijmakers, Q. A. (1999). Effectiveness of different missing data treatments in surveys with Likert-type data: Introducing the relative mean substitution approach. Educational and 
Psychological Measurement, 59, 725-748. Retrieved from

doi:10.1177/0013164499595001

Robertson, E., Grace, S., Wallington, T., \& Stewart, D. E. (2004). Antenatal risk factors for postpartum depression: A synthesis of recent literature. General Hospital Psychiatry, 26, 289-295. Retrieved from doi:10.1016/j.genhosppsych.2004.02.006

Ross, L. E. (2005). Perinatal mental health in lesbian mothers: A review of potential risk and protective factors. Women \& Health, 41(3), 113-128. Retrieved from doi:10.1300/J013v41n03_07

Ross, L. E., Steele, L., Goldfinger, C., \& Strike C. (2007). Perinatal depressive symptomatology among lesbian and bisexual women. Archive of Women's Mental Health, 10(2), 53-59. Retrieved from doi:10.1007/s00737-007-0168-x

Santoro, K. L., \& Peabody, H. (2010, June). Identifying and Treating Maternal Depression: Strategies \& Considerations for Health Plans. (National Institute of Healthcare Management Foundation Issue Brief). Retrieved from http://nihcm.org/pdf/FINAL_MaternalDepression6-7.pdf

Santos, I. S., Matijasevich, A., Rodrigues, D. M., Barros, A. J., \& Barros, F. C. (2010). Longlasting maternal depression and child growth at 4 years of age: a Cohort Study. Journal of Pediatrics, 157, 401-406. Retrieved from doi:10.1016/j.jpeds.2010.03.008

Segun, L., Potvin, L., St-Denis, M., \& Loiselle, J. (1995). Chronic stressors, social support, and depression during pregnancy. Obstetrics \& Gynecology, 85(4), 583-589. Retrieved from doi:org/10.1016/0029-7844(94)00449-N

Shapiro, D. N., Peterson, C., \& Stewart, A. J. (2009). Legal and social contexts and mental health among lesbian and heterosexual mothers. Journal of Family Psychology, 23(2), 255-262. Retrieved from doi:10.1037/a0014973

Smarr, K. L. (2003). Measures of depression and depressive symptoms: The Beck Depression Inventory (BDI), Center for Epidemiological Studies-Depression Scale (CES-D), Geriatric Depression Scale (GDS), Hospital Anxiety and Depression Scale (HADS), and Primary Care Evaluation of Mental Disorders-Mood Module (PRIME-MD). Arthritis \& Rheumatism, 49, S134-S146. Retrieved from doi:10.1002/art.11410

Solomon, D. A., Keller, M. B., Leon, A. C., Mueller, T. I., Lavori, P. W., Shea, M. T.,...Endicott, J. (2000). Multiple recurrences of major depressive disorder. American Journal of Psychiatry, 157(2), 229-233. Retrieved from 10.1176/appi.ajp.157.2.229

Sorensen, L., \& Roberts, S. J. (1997). Lesbian uses of and satisfaction with mental health services: Results from Boston Lesbian Health Project. Journal of Homosexuality, 33, 3549. Retrieved from doi:10.1300/J082v33n01_03 
Stacey, J., \& Biblarz, T. J. (2001). (How) does the sexual orientation of parents matter? American Sociological Review, 66, 159-183. Retrieved from http://www.jstor.org/stable/2657413

Steele, L. S., Ross, L. E., Epstein, R., Strike, C., \& Goldfinger, C. (2008). Correlates of mental health service use among lesbian, gay, and bisexual mothers and prospective mothers. Women \& Health, 47(3), 95-112. Retrieved from doi: 10.1080/03630240802134225

Substance Abuse and Mental Health Services Administration. (2012). Results from the 2011 National Survey on Drug Use and Health: Summary of national findings; table 1.53B major depressive episode (MDE) in the past year among persons aged 18 or older, by gender and detailed age category: Percentages, 2010 and 2011. NSDUH Series H-44, HHS Publication No. (SMA) 12-4713. Rockville, MD: Substance Abuse and Mental Health Services Administration. Retrieved from http://www.samhsa.gov/data/NSDUH/2k11MH_FindingsandDetTables/Index.aspx

Tasker, F., \& Golombok, S. (1995). Adults raised as children in lesbian families. American Journal of Orthopsychiatry, 65(2), 203-215. Retrieved from doi:http://dx.doi.org/10.1037/h0079615

Trettin, S., Moses-Kolko, E. L., \& Wisner, K. L. (2006). Lesbian perinatal depression and the heterosexism that affects knowledge about this minority population. Archives of Women's Mental Health, 9, 67-73. Retrieved from doi:10.1007/s00737-005-0106-8

Turner, K. M., Sharp, D., Folkes, L., \& Chew-Graham, C. (2008). Women's views and experiences of antidepressants as a treatment for postnatal depression: A qualitative study. Family Practice, 25(6) 450-455. Retrieved from doi: 10.1093/fampra/cmn056

van Brunt, R. A. (2009). An online support group intervention for Asian American lesbian and bisexual women. (Doctoral Dissertation). Retrieved from ProQuest Dissertations \& Theses. (3316181).

van Bussel, J. C., Spitz, B., \& Demyttenaere, K. (2006). Women’s mental health before, during, and after Pregnancy: A population-based controlled cohort study. Birth, 33(4), 297-302. Retrieved from doi:10.1111/j.1523-536X.2006.00122.x

Wayment, H. A., \& Peplau, L. A. (1995). Social support and well-being among lesbian and heterosexual women: A structural modeling approach. Personality and Social Psychology Bulletin, 21, 1189-1199. Retrieved from doi:10.1177/01461672952111007

White, J. C., \& Levinson, W. (1995). Lesbian health care: What a primary care physician needs to know. Western Journal of Medicine, 162, 463-466. Retrieved from http://www.ncbi.nlm.nih.gov/pmc/journals/183/

Zimet, G. D., Dahlem, N. W., Zimet, S. G., \& Farley, G. K. (1988). The Multidimensional Scale of Perceived Social Support. Journal of Personality Assessment, 52, 30-41. Retrieved from doi:10.1207/s15327752jpa5201_2 
Zimet, G. D., Powell, S. S., Farley, G. K., Werkman, S., \& Berkoff, K. A. (1990). Psychometric characteristics of the Multidimensional Scale of Perceived Social Support. Journal of Personality Assessment, 55, 610-17. Retrieved from doi:10.1080/00223891.1990.9674095 